\title{
Characterization of Weathered Soft Rock Mass by Index
}

\section{Tests}

\author{
Fernandes Leão $\mathbf{M}^{*}$ \\ Federal University of Vicosa, Brazil \\ *Corresponding author: Marcio Fernandes Leao, Federal University of Vicosa, Brazil, \\ Tel: (31)38992740; Email: marciotriton@hotmail.com
}

\section{Research Article \\ Volume 1 Issue 1}

Received Date: November 27, 2018

Published Date: December 10, 2018

\section{Abstract}

The understanding of geotechnical and geomechanical rock mass behavior is challenging, mainly regarding weathered parts, since they may trigger stability issues. Soft Rocks, as phyllite, are known to enhance these problems. In this case, a road cut on a highway between the cities of Ouro Preto and Mariana (MG - Brazil) was studied, showing a particular weathering zone with changing conditions. After morphological description and geological fragmentation (using geological hammer, the Schmidt hammer and a switchblade) of the weathering zone, tests were done on rock matrix and rock mass in order to identify the discontinuity features. Physical properties were determined by physical index, using the point load test and slake durability test. The results permit to define the weathering zone, showing some huge anisotropy and heterogeneity in the rock properties.

Keywords: Index-Tests; Weathering Profile; Quadrilátero Ferrífero

\section{Introduction}

The weathering grade is defined by an ensemble of processes that lead to a changing of the mechanical rock properties, concerning the decrease of its resistance, resulting in soil formation. In turn, the weathered grade may also be defined by the set of examples from the same lithological type that shows weathering petrographic, technology and mechanical properties into limits defined [1].

Weathering - associated to natural slopes - triggers great instability issues, common in Brazil, particularly in the Quadrilátero Ferrífero (MG) area, where instabilities are shown on road cut and mining slopes. When these sections are formed in soft rocks as phyllites, these issues are increased, mainly due to the rocks index properties and weakness planes along the foliation.
On unaltered metapelites, the weather action increases the anisotropy, due to different temperature and pressure responses or weakness planes formation that influence the geomechanical context, as well as a changing of the fabric initial direction relating to the rock structure [2]. It could also be motivated by mineralogical and physical (color, density, porosity, permeability, friability and resistance) changes. Chemical factors are also motivators for the increasing of the anisotropy, since they could affect the rock resistance by silica leaching, for example.

Researches about geological-geotechnical behavior of weathered profiles of low metamorphic grade rocks are few, even though there are many efforts. In addition, the great number of propositions and terminologies makes it hard to understand and apply some terms, mainly because classifications depend on the weathering active 


\section{International Journal of Paleobiology \& Paleontology}

process and not just on the rock initial features and its geological and structural context $[1,3]$.

The tests to index properties characterization and acquisition may indicate the rocks material behavior, such as its durability, making possible correlations about mechanical properties, as the resistance and deformability [4].

Simple tests in situ were recommended to evaluate weathering intensity. They were performed on rock's matrix using the geological hammer and a switchblade, the main objective was the establishment of homogeneous groups in order to map them along the rock mass [5-7].

Beyond these tests, proposed the slake durability test in order to mark a transition zone between weathered rock matrix and the soil state [8]. Another important and efficient test is the sclerometry, by sclerometer or Schmidt Hammer. Due to its simplicity, it allows a measure in situ without any specimen preparation. The presence of roughness on tested surfaces as well as discontinuities nearby can generate disperse values 1 being very sensitive on soft rocks (with a $R$ value rebound lower than 10) [9].

According to Brown [10], the Schmidt Hammer and the Point Load Test (PLT) have few applications to low resistance rocks, however good correlation is obtained to soft rocks with higher resistance by using its uniaxial compressive strength. The simple compression resistance can also be obtained to the hardness of the material, once there is not only one single correlation for all kind of rocks [11].

Leão, et al. [12] achieved good results to the weathering evaluation on phyllites using the Schmidt Hammer, however the estimative of the Rock Quality Designation (RQD) by volumetric index of the joints $\left(\mathrm{J}_{\mathrm{v}}\right)$, proposed by Palmstrom [13], was not representative.

The PLT triggers ruptures in rocks specimen, due to their compression between two hard metal conic tips, which spread traction fractures parallels to the load axis. It is a simple, quick and easy test to do, because the specimens can possess many shapes and sizes. The test is also easy to reproduce, due to the advantageous portability of its equipment [14].

For this reason, it is very recommended to rock characterizations and it can be related to the uniaxial compression strength [14]. In clay rocks, as mudstones and siltstones, with resistance lower than $25 \mathrm{MPa}$, this test is not recommended, thanks to conic tips penetration in the specimen [15]. In this case, some corrections in the results are crucial [14].

Hence, the advantages of using simple tests in situ are demonstrated along this paper in order to assist the mapping of rock massifs. This primarily evaluation of the weathering intensity assists engineering and mining projects in the Quadrilatero Ferrífero area (Minas Gerais State - Brazil).

As a study object, a weathering front exposed on a road cut between Mariana and Ouro Preto cities was selected, being defined four weathering grades of phyllites, that is, fresh rock (W1), slightly weathered rock (W2), moderately weathered rock (W3) and highly weathered rock (W4).

\section{Material and Methods}

Two steps set the methodology stage, the first one includes the identification and classification of the weathering grades, using an adaptation of the International Society of Rock Mechanics - ISRM [16], rock blocks collection, weathering profiles description as well as tests using geological hammer, the Schmidt hammer and a switchblade. In the second step, some index properties were defined, such as dry and wet density, porosity and water absorption. Furthermore, the second step involved the PLT and the slake durability test as well.

\section{Weathering Profiles Classification}

The weathering grade classification was based on the ISRM classification. The characterization of the discontinuities, aperture, filling, spacing and persistence were characterized by simple matrix tests (switchblade scratch and geological hammer hits) and the Schmidt Hammer test, as suggested by Palmstrom [13].

\section{Physical Description}

The definition of the index properties was obtained according to the ISRM [16]. Ten samples were prepared, one for each weathering grade (W1 to W4). Each one of them possessed defined geometry and weight between $0.4 \mathrm{~kg}$ and $0.6 \mathrm{~kg}$. Afterwards, they were dried in a greenhouse for $24 \mathrm{~h}\left(105^{\circ} \mathrm{C}\right)$, this process aimed the measurement of the dry density. On the opposite, the saturated density was obtained by drowning the sample in distillated water during $24 \mathrm{~h}$. Those were also subjected 


\section{International Journal of Paleobiology \& Paleontology}

to vacuum throughout the process of submersion, in order to ensure the total saturation of the samples. The porosity and water absorption were determined based on the volumetric dimensions and weights [16].

The durability was determined by the slake durability test [14]. As recommended, ten fragments (from W1 to W4) possessing round edges underwent moistening and drying cycles of $200 \mathrm{rpm}$ during 10 minutes each. After the first and the second cycle, the slake index could be determined ( $I_{d 1}$ and $I_{d 2}$, respectively).

\section{Mechanical Description}

The sclerometeric index (R), obtained by the dimensionless value of $\mathrm{R}$, could be determined in situ using an adaptation of the NBR 7584 Standard [17]. Following such Standard, an area with $20 \mathrm{~cm}$ per $20 \mathrm{~cm}$ was hit 20 times, maintaining the direction of the Schmidt Hammer orthogonal to the surface, which, in this case, was the foliation plane.
The ISRM Standard [14] was used for the PLT. Thus, ten samples (from W1 to W4) were selected obeying the appropriate proportion of height, width and depth proper to the irregular condition. The rock was pointily loaded between two cones. As a result, the resistance index to point load $\left(\mathrm{I}_{\mathrm{s}}\right)$ could be determined, normalized to a 50 mm diameter $\left(\mathrm{I}_{\mathrm{s}(50)}\right)$.

\section{Results and Discussion}

\section{Weathering Profile Description}

Figure 1 shows the weathering profile after the definition of the weathered classes. The surface survey was carried out in a cut slope situated near the Km 140 on the BR-356 highway, which connects the cities of Mariana (MG) and Ouro Preto (MG) in Brazil. The Table 1 main principal characteristics of discontinuities of the weathering grades on the phyllite slope.

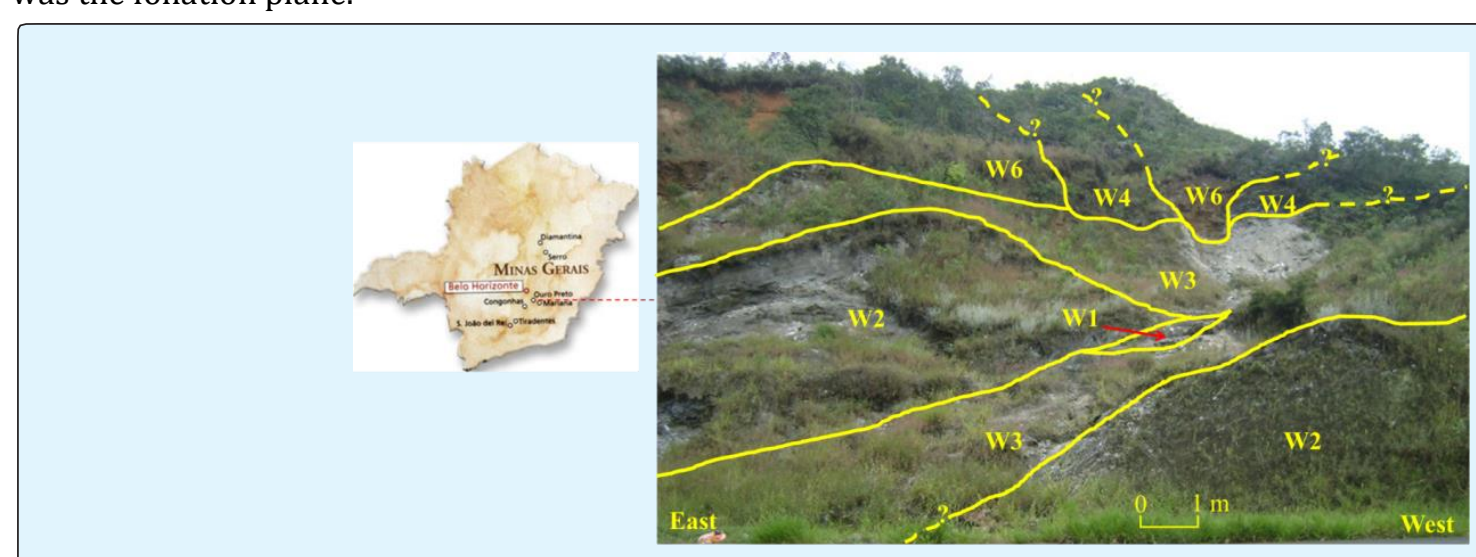

Figure 1: Political map of Minas Gerais, Brazil (left). The location of the approximate study area is shown on the dashed red line. Weathering profile classification (right).

\begin{tabular}{|c|c|c|c|c|}
\hline Weathering grades & W1 & W2 & W3 & W4 \\
\hline Fractures & The rock has fracture families that are nearly orthogonal and parallel to the foliation \\
\hline Aperture $(\mathrm{cm})$ & $0.0-0.2$ & $0.2-0.5$ & $0.5-0.8$ & $0.8-2.0$ \\
\hline Spacing $(\mathrm{cm})$ & $>100$ & $100-50$ & $50-5$ & $<1$ \\
\hline $\mathrm{J}_{\mathrm{v}}$ (fractures $/ \mathrm{m}^{3}$ ) & 3-Jan & 3-Jan & $10-\mathrm{Mar}$ & $10-\mathrm{Mar}$ \\
\hline
\end{tabular}

Table 1: Main characteristics of the discontinuities from the evolution of the weathering in the phyllites.

The rock presents very fine granulometry, without possible differentiation of mineralogy by magnifying glass at the magnification rate of 10 times. The weathering grades are mainly distinguished by the color variation (W1 - silver gray, W2 - less bright silver gray, W3 reddish silver, W4 - greenish / yellowish gray). Tests using switchblade and geological hammer evidence the decrease of the physical and mechanical properties as the weathering evolve. The main fractures families take place primarily parallel to the foliation planes and secondarily orthogonal to those planes. As the weathering evolves, that is, from $\mathrm{W} 1$ to $\mathrm{W} 4$, the increase of the aperture, 


\section{International Journal of Paleobiology \& Paleontology}

persistence and $\mathrm{J}_{\mathrm{v}}$ occur. On the other hand, the discontinuities spacing decreases.

\section{Physical Properties}

Figures $2 \& 3$ show the results obtained for the dry density, saturated density, porosity and water absorption.

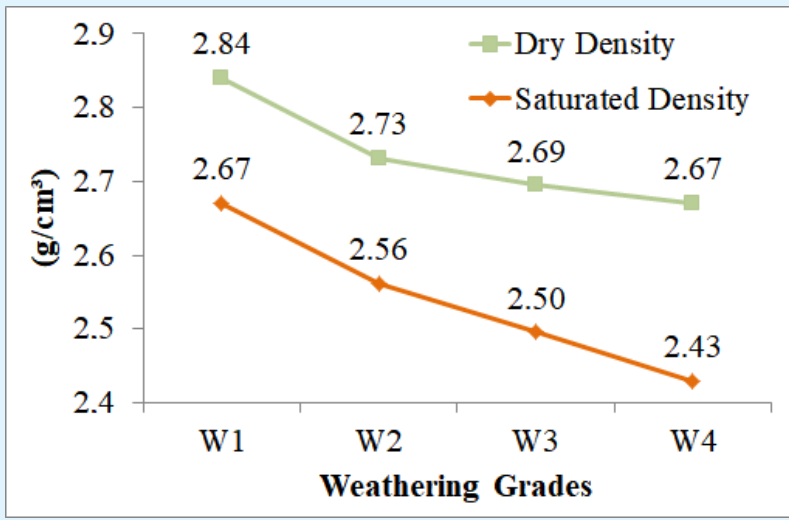

Figure 2: Average values for dry density and saturated density according to weathering grades.

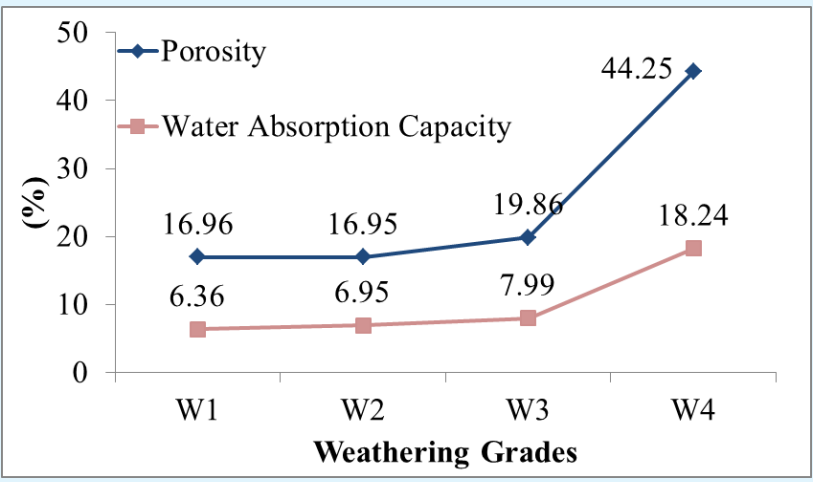

Figure 3: Average values for porosity and water absorption capacity according to weathering grades.

The porosity tends to increase along with water absorption as there is an evolution of the weathering grade. Although metamorphic rocks generally have low porosity, the weathering action allows this parameter to be influenced by the development of micro fissures around the grains contours and in the joints. Those features allow the formation of discontinuity along the foliation planes. The specific weight provides important features about the mineralogy and the weathering grade.
In this case, it is possible to notice that both the dry and the saturated density mass decrease as the weathering grade increases, but in a less intense manner than the increase of the porosity and the water absorption, exposing an important influence of the physical weathering over those properties. Figure 4 show the results of the durability test.

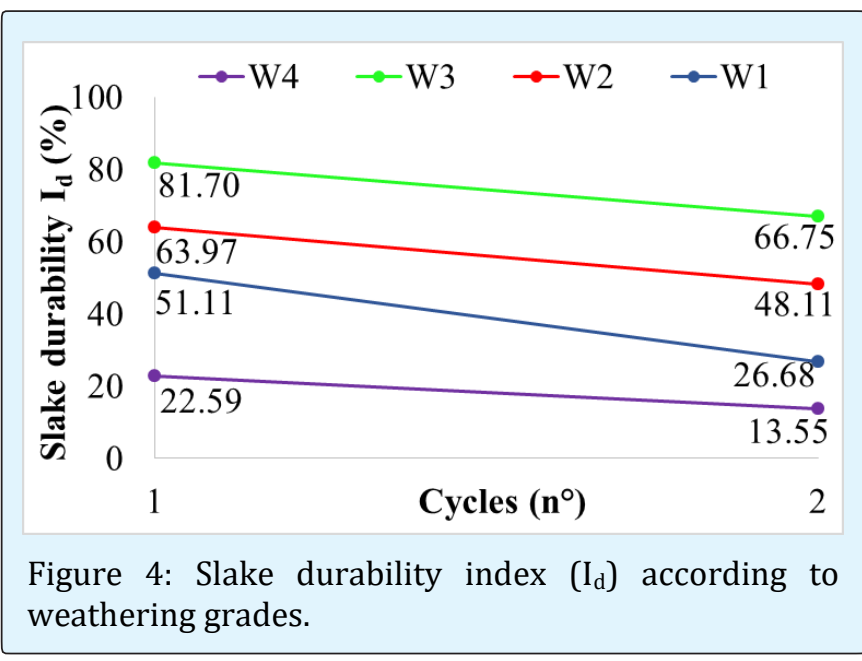

Following the results, it is clear that the durability does not follow the weathering's evolution directly. The level W3 showed the highest durability (medium durability) followed by W2 and W1 (both with low durability), the exception being level W4, which presented low durability, which was actually expected. The foliation plans facilitated the physical degradation during the test, due to the high opening and persistence of the discontinuities, which occur preferentially parallel to the foliation. Considering this aspect only, the sanest level (W1) should present the highest durability comparing to the others, since the foliation planes are little highlighted though visible. Nevertheless, the presence of mineral cemented levels, coming from processes that are parallel to the weathering and concordant to the foliation planes in W2 and W3, add higher durability in W1 than the matrix durability itself.

\section{Mechanical Properties}

Figure 5 shows data obtained from the Schmidt Hammer. The average values of R were: 19.78 (W1), 17.63 (W2), 14.08 (W3) e 12.38 (W4), reducing as the weathering level increases. The surficial durability of the weathering grades is related to the weathering process and consequently correlated to the rocks mineralogy. 


\section{International Journal of Paleobiology \& Paleontology}

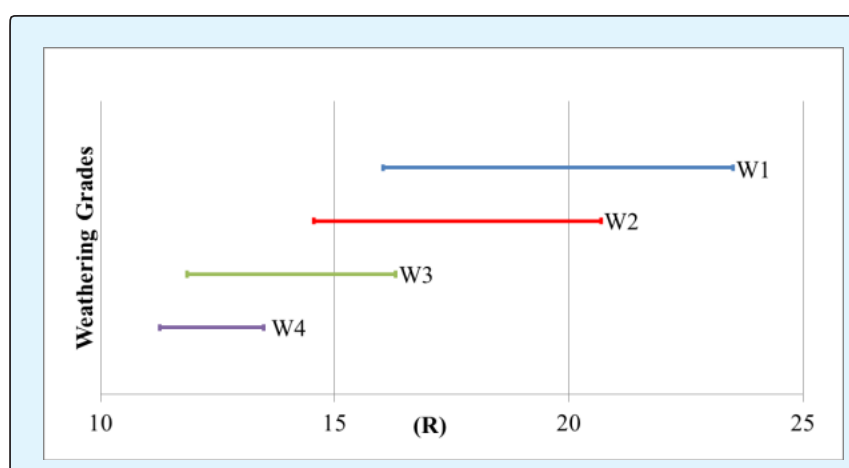

Figure 5: R values according weathering grades.

Figure 6 presents the results obtained from the PLT. Basing on the values of $I_{s(50)}$ it is apparent the resistance decreases as the weathering grade increases. Marques \& Williams (2015) [18] achieved, for several weathering grade of Bunya Phyllite (Australia), similar physical features of W2 to W4 [16]. Their values were $20 \%$ higher than those of this study, evidencing the phyllites great heterogeneity.

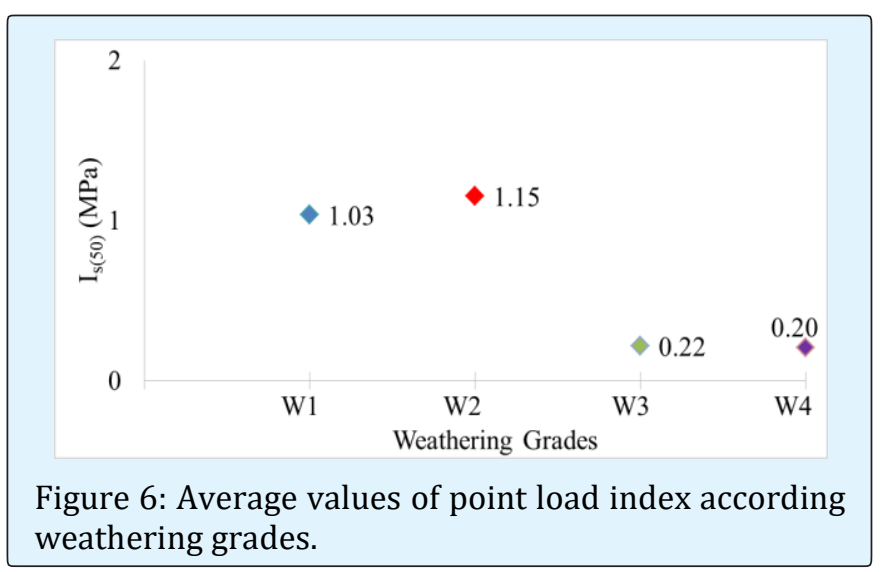

Next, are presented relations between the porosity $(\eta)$ and the sclerometric index (R) Figure 7 and point load index Figure 8, respectively.

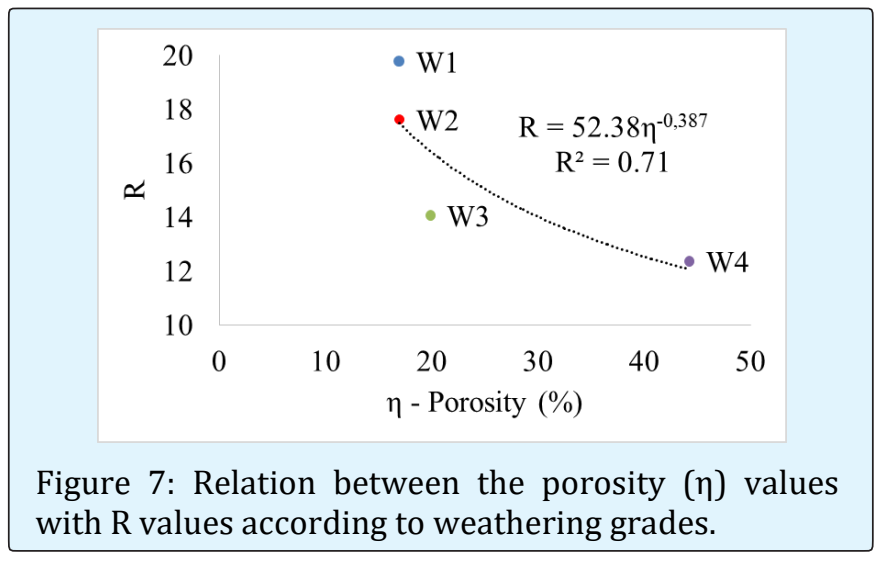

Fernandes Leão M. Characterization of Weathered Soft Rock Mass by Index Tests. Int J Paleobiol \& Paleontol 2018, 1(1): 000104.

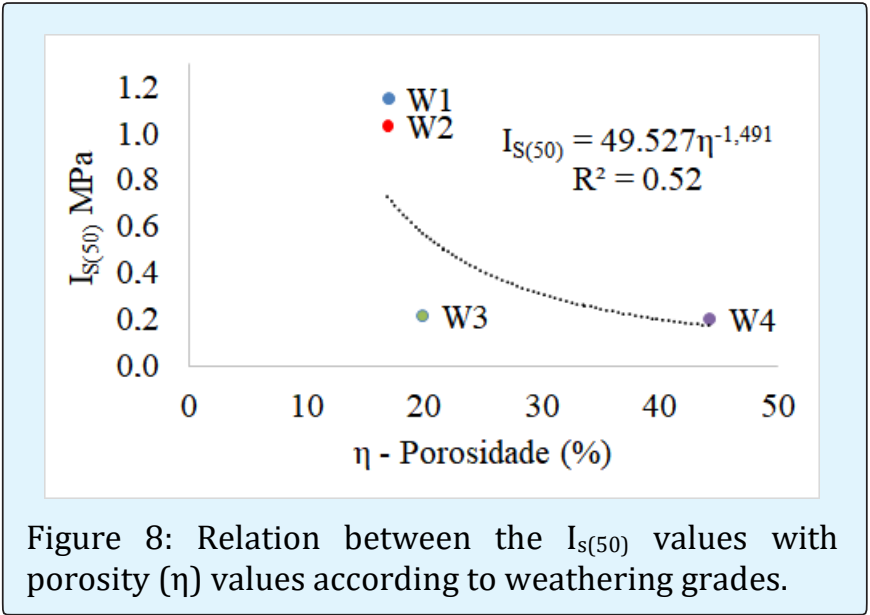

The resistance decrease is observed following Figures $7 \& 8$, including both matrix toughness and $\mathrm{I}_{\mathrm{s}(50)}$. That happens as the porosity increases, which evidences the influence of the weathering process over the mechanical properties of the phyllites.

\section{Conclusion}

The effects of weathering, under tropical climate, in phyllite were explored in this paper. It is noted that the weathering front does not gradually evolve from fresh phyllite at the bottom to highly weathered rock at the top of the slope. In this way, the presence of discontinuities plays an important role in the distribution of these weather degrees in the rock mass. The traditional criteria for describe the weathering by rock matrix should be used with caution for typical weak rocks. In the rock matrix scale, physical properties show significant discontinuities, particularly pore size distribution and spot loading curves force. There is a great influence of the discontinuities in the physical and mechanical properties, parallel to the foliation, especially between $\mathrm{W} 2$ and $\mathrm{W} 3$, in relation to the weathering action. However, comparing with more extreme levels (W1 and W4), the effect of weathering on the rock is better defined. In other words, the presence of discontinuities is determined to the weathering action; not only because it exposes the rock massif interior part to the weathering action, but it also allows the percolation of many fluids that accelerate this process.

Likewise, the preliminary estimate of the weathering effect, based on the index test, was effective, even in rocky massifs that tend to expose much heterogeneity. Thus, the evaluation, following such simple, quick and low cost methodology, showed many advantages at determining the physical and mechanical properties of rocky massifs. 


\section{International Journal of Paleobiology \& Paleontology}

\section{References}

1. Leão MF (2011) Geological-Geomechanical Modeling of the San Juan Dam, Dominican Republic. MSc Dissertation, Department of Geology, Federal University of Rio de Janeiro (in portuguese).

2. Heng S, Guo Y, Yang C, Daemen J, Li Z (2015) Experimental and Theoretical Study of the Anisotropic Properties of Shale. International Journal of Rock Mechanics and Mining Sciences 74: 58-68.

3. Leão MF, Barroso EV, Polivanov H, Marques EAG, Vargas Jr AE (2017) Weathering of Metapelites from the Quadrilátero Ferrífero Mineral Province, Southeastern Brazil. Bulletin of Engineering Geology and the Environment 76: 1-15.

4. Oliveira R (1993) Weak Rock Material. The Engineering Geology of Weak Rock. In: 26 ${ }^{\text {th }}(\mathrm{edn})$ Annual Conference of the Engineering Group of the Geological Society, Annals. Leeds, United Kingdom, 8: 5-15.

5. GCO Geotechnical Control Office (1988) Guide to Rock and Soil Descriptions. Geotechnical Control Office, Hong Kong Government Printer, Hong Kong.

6. Raj JK (1983) Characterization of Weathering Profiles Developed Over Granitic Bedrock In Humid Tropical Areas. In: International Seminar on Laterite, Annals. Kuala Lumpur 1: 355-374.

7. Gamon TI (1983) A Comparison of Schemes for Engineering Description and Classification of Weathered Rocks in Hong Kong. Bulletin of International Association of Engineering Geology 28: 225-232.

8. Lee SG, Freitas MH (1988) Quantitative Definition of Highly Weathered Granite Using the Slake Durability Test. Géotechnique. 38: 635-640.

9. Pinho B (2003) Geotechnical Characterization of Low Resistance Rock Massifs- The Flysch of Baixo Alentejo. PhD Thesis Évora University (in portuguese).
10. Brown RT (1981) Rock Characterization Testing and Monitoring. ISRM Suggested Method. Pergamon Press, 211.

11. Xu S, Grasso PE, Mahtab A (1990) Use of Schmidt Hammer for Estimating Mechanical Properties of Weak Rock. In: 6 Int. Congress, Int. Assoc. Engineering Geology, Annals... Amsterdam 1: 511-519.

12. Leão MF, Marques EAG (2006) Morphology And Geotechnical Characterization of A Phyllite Weathering Profile Developed Under Tropical Climate. In: 5 International Conference on Geotechnical and Geophysical Site Characterization, Annals...Queensland.

13. Palmstrom A (2005) Measurements of and Correlations between Block Size and Rock Quality Designation (RQD). Tunnels and Underground Space Technology 20(4): 362-377.

14. (1981) ISRM International Society of Rock Mechanics. Basic geotechnical description of rock masses. Int Society of Rock Mechanics. Commission on the Classification of Rock and Rock Masses. Int J Rock. Mechanics Min. Sci Geomech Abstr 18: 85-110.

15. Hawkins B, Pinches GM (1992) The Engineering Description of Mudrocks. Quarterly Journal Engineering Geology, London, 25: 17-30.

16. (2015) ISRM International Society of Rock Mechanics. The ISRM Suggested Methods for Rock Characterization, Testing and Monitoring: 2007-2014, $5^{\text {th }}($ edn), R. Ulusay (Editor).

17. NBR 7584: Hardened concrete - Evaluation of surface hardness by reflecting esclerometer - Test method. Rio de Janeiro, 2012 (in portuguese).

18. Marques EAG, Williams D J (2005) Weathering Profiles of Bunya Phyllite in Southwest Brisbane - a Geotechnical Approach. In: 12 Australia New Zealand Conference on Geomechanics, 2015. Wellington. Annals... Wellington: Changing the Face of the Earth 1: 1-8. 